\title{
A CONVENIENT METHOD FOR LECITHIN PURIFICATION FROM FRESH EGGS\#
}

\author{
Flavio A. Maximiano \\ Departamento de Química Fundamental, Instituto de Química, Universidade de São Paulo, São Paulo - SP, Brasil
}

Marcia A. da Silva, Katia R. P. Daghastanli, Pedro S. de Araujo, Hernan Chaimovich e Iolanda M. Cuccovia*

Departamento de Bioquímica, Instituto de Química, Universidade de São Paulo, CP 26077, 05513-970 São Paulo - SP, Brasil

Recebido em 11/2/08; aceito em 17/3/08; publicado na web em 23/4/08

\begin{abstract}
The increasing demand for fatty acid-free lecithin required modifications in existing purification methods. In this technical note we describe a purification procedure with the following steps: a) homogenization and extraction of yolks obtained from fresh eggs with acetone, b) solubilization with ethanol and solvent elimination and c) repeated solubilization/precipitation with petroleum ether/ acetone. This crude extract was chromatographed on neutral alumina, which was exhaustively washed with chloroform before elution with chloroform:methanol, allowing the sequential separation of fatty acids and lecithin. Chromatographic behavior and mass spectra of the product are presented. This fast procedure yields fatty acid-free lecithin at a competitive cost.
\end{abstract}

Keywords: lecithin; purification; phosphatidylcholine.

\section{INTRODUCTION}

It is amazing that after 80 years, ${ }^{1,2}$ the following paragraph could be part of this introduction: "methods employed in other laboratories as well as in our own are costly and time-consuming; second, judging from the numerous and frequent requests for the material which we have had from American and European colleagues, there seems to exist among biologists a considerable need for pure phosphatides". ${ }^{2}$

Since then numerous methods for lecithin purification have been described. ${ }^{1-11}$ In general, these methods start with fresh eggs, since the dried yolk preparations usually contain both lysolecithin and, correspondingly, free fatty acids. In fact, the dependence of the extraction method with the source of lecithin was noted in the late 1920's: "the conditions for the preparation of the crude extracts may vary, depending on the starting material". ${ }^{2}$ The methods for lecithin preparation have varied but can be grouped into three classes, i.e., extraction and $\mathrm{CdCl}_{2}$ precipitation, ${ }^{2,3}$ extraction and alumina and/or silica chromatography, ${ }^{4,5}$ and high performance liquid chromatography. ${ }^{9}$ The increasing use of lecithin for diverse nanostructures for drug delivery ${ }^{12}$ and vaccination ${ }^{13}$ has, at the same time, increased the number of suppliers of pure lecithin and increased the pressure for the preparation of lecithin of higher purity and lower cost. We have used lecithin for various purposes over the last decades and have continuously adapted the preparation methods to accommodate internal and external demands. As a general rule, we have found it easier to purify egg lecithin starting from fresh eggs than to try to purify lecithin from (several) suppliers of either dried eggs or lecithin of variable degrees of purity. This is especially important when fatty acid-free lecithin is required.

In this technical note we describe a relatively easy, inexpensive and reproducible method for obtaining fatty acid-free lecithin in a gram-scale.

\footnotetext{
\# To the memory of Helena Maria Carvalho Ferraz, scientist and friend.

*e-mail: imcuccov@iq.usp.br
}

\section{MATERIAL AND METHODS}

\section{Materials}

Analytical grade acetone, ethanol, petroleum ether, chloroform (with 1\% ethanol), methanol and acetic acid were from J. T. Baker. Aluminium oxide 90 active neutral (70-230 mesh ASTM) and Silica Gel 60 plates for TLC were from Merck.

\section{Methods}

Thin layer chromatography (TLC): silica gel plates were activated at $120{ }^{\circ} \mathrm{C}$ for $1 \mathrm{~h}$. Chloroform solutions $(40 \mathrm{mg} / \mathrm{mL})$ of standards and the collected fractions were prepared and $5 \mu \mathrm{L}$ were applied to silica gel TLC plates.

Fatty acids and other apolar compounds were separated from lecithin by TLC using petroleum ether: ethylic ether: acetic acid (90:10:1 v/v) as the solvent system (TLC-A) while lecithin remains at the origin. Lecithin and other phosphatides migrate in TLC silica plates using chloroform: methanol: water (65:35:3 v/v) (TLC-B) and the apolar contaminants migrate with the solvent front.

After the development, the plates were sprayed with molybdate solution (Kamp et al. and references therein). ${ }^{14}$ The appearance of a blue color, after ca. $5 \mathrm{~min}$ at room temperature, indicated phosphorous containing compounds. After $10 \mathrm{~min}$ at $120{ }^{\circ} \mathrm{C}$, all the organic compounds were charred and appeared as black spots.

\section{ESI mass spectra analyses}

The analyses of the fractions eluted from the alumina column were carried out on a Quattro II Micromass mass spectrometer with Z-spray ${ }^{\mathrm{TM}}$ ion source (Manchester, UK). The samples were analyzed by direct injection in the mass spectrometer, using methanol as the mobile phase and a flow rate of $0.05 \mathrm{~mL} / \mathrm{min}$. The ionization mode was electrospray positive $\left(\mathrm{ESI}^{+}\right)$. The sample and extractor cone voltage were $20 \mathrm{~V}$. The source and desolvation temperatures were set at $80{ }^{\circ} \mathrm{C}$ and the capillary potential was $3.5 \mathrm{kV}$. The flow rate of drying and nebulizing gas was optimized at 350 and $15 \mathrm{~L} / \mathrm{h}$. Full scan data were acquired over a mass range from 300 to $900 \mathrm{~m} / \mathrm{z}$. 
Data were processed by the software Mass Lynx NT, version 3.2 (Micromass, Altricham, UK).

\section{Lecithin crude extract preparation (CE)}

Sixty fresh egg yolks (ca. 800 g) were separated, carefully washed with water and passed through a sieve to remove the membranes. $2 \mathrm{~L}$ of cold acetone $\left(4^{\circ} \mathrm{C}\right)$ were added to the yolk suspension and the mixture was homogenized with a mechanical homogenizer equipped with a glass helix during $5 \mathrm{~min}$. The homogenate was maintained for $1 \mathrm{~h}$ at $4{ }^{\circ} \mathrm{C}$ to precipitate crude phospholipids and proteins. The suspension was filtered (Büchner) and the precipitate, ppt1, washed $(5 \mathrm{x}, 400 \mathrm{~mL}$ acetone each). The acetone filtrate, which contains neutral fats and pigments, ${ }^{3,5}$ was discarded and the residual solvent of ppt1 was eliminated under vacuum. Ppt1 was transferred to a beaker, $2 \mathrm{~L}$ of cold $\left(4^{\circ} \mathrm{C}\right)$ ethanol were added and the suspension was mechanically homogenized (5 min). The mixture was filtered (Büchner) and the precipitate reextracted with ethanol $(1 \mathrm{~L})$. The ethanol extracts, which contain the phospholipids, were combined and the solvent removed in a rotatory evaporator $\left(\mathrm{T}<40{ }^{\circ} \mathrm{C}\right)$. The resulting very crude lecithin extract, VCE, was dissolved in petroleum ether $(400 \mathrm{~mL})$, acetone $\left(2 \mathrm{~L}, 4{ }^{\circ} \mathrm{C}\right.$ ) was added to precipitate the lecithin. After $2 \mathrm{~h}$ at $4{ }^{\circ} \mathrm{C}$, the supernatant cleared, and the solvent was separated from the precipitate by decantation. The crude lecithin extract, CE, was dissolved again in $400 \mathrm{~mL}$ of petroleum ether and the precipitation process was repeated. After this procedure, $\mathrm{CE}$ was solubilized in chloroform and evaporated at reduced pressure. This step was needed to remove the residual solvents instead of filtering CE. CE is a greasy material which obstructed the filter and lead to loss of material and lecithin oxidation.

The resulting $\mathrm{CE}$ was distributed into tubes containing $2 \mathrm{~g}$ each and maintained at $-80{ }^{\circ} \mathrm{C}$, under vacuum. The $\mathrm{CE}$ yield was $45 \mathrm{~g}$ corresponding to $5.6 \%$ of the initial egg yolk total mass. This yield compared favorably with that obtained using other procedures. ${ }^{3} \mathrm{~A}$ flow chart of the extraction procedure is shown in Scheme 1.

\section{Yolks from fresh eggs $(800 \mathrm{~g})$}

1) Homogenize in acetone (2 L)

2) Filter

3) Wash the precipitate, (acetone $2 \mathrm{~L}$ )

ppt1

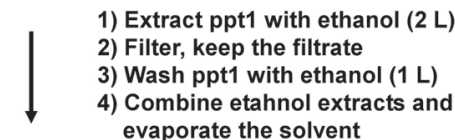

Very Crude Extract VCE

1) Dissolve in petroleum ether $(0.4 \mathrm{~L})$ 2) Precipitate with acetone $(2 \mathrm{~L})$

3) Decant the solvent, keep the precipitate

4) Repeat steps 1 to 3

\section{Crude Extract, CE}

\section{1) Dissolve CE in Chloroform}

2) Remove the solvents

Scheme 1. Flow chart of the lecithin extraction procedure

\section{Alumina column chromatography}

A suspension of $80 \mathrm{~g}$ of neutral Alumina (activated at $120{ }^{\circ} \mathrm{C}$ for $12 \mathrm{~h}$ ) in chloroform was added to a glass column $(35 \mathrm{~cm} \times 2$ $\mathrm{cm}$, Teflon tap, fritted glass bottom). Alumina fines were not eliminated before lecithin elution because, at the end of purification, the fractions were individually concentrated, diluted in a small amount of methanol and then passed through a $0.22 \mu \mathrm{m}$ nylon filter.

$2.0 \mathrm{~g}$ crude lecithin, dissolved in $3.5 \mathrm{~mL}$ of chloroform, was applied to the column. Column flux was $4 \mathrm{~mL} / \mathrm{min}$ and $100 \mathrm{~mL}$ fractions were collected. CE was eluted, successively, with: chloroform $(1.0 \mathrm{~L})$; chloroform: methanol $(95: 5 \mathrm{v} / \mathrm{v}, 0.1 \mathrm{~L})$ and chloroform: methanol $(9: 1 \mathrm{v} / \mathrm{v}, 0.5 \mathrm{~L})$. Each fraction was evaporated under reduced pressure and maintained in a desiccator under vacuum at $-20{ }^{\circ} \mathrm{C}$.

The lecithin containing fractions were pooled, dissolved in methanol, and distributed into tubes containing approximately 100 $\mathrm{mg}$ of lecithin each. Methanol was evaporated under a $\mathrm{N}_{2}$ flux; the tubes were maintained for about $1 \mathrm{~h}$ in a desiccator under vacuum to eliminate the residual solvent. The tubes were sealed under vacuum and stored at $-80{ }^{\circ} \mathrm{C}$.

\section{RESULTS AND DISCUSSION}

\section{Lecithin purification}

The dry weights of each fraction eluted from the Alumina column are in Table 1. The sum of the masses of fractions 1 to 12 gave ca. $170 \mathrm{mg}$ and fractions 13 to 15 yielded $610 \mathrm{mg}$ of pure lecithin, a yield of $30.5 \%$ respective to $\mathrm{CE}$.

Table 1. Dry weights of the fractions eluted from the alumina column

\begin{tabular}{lcc}
\hline Fraction & Solvent & mass (mg) \\
\hline 1 & $\mathrm{HCCl}_{3}$ & 20 \\
2 & $\mathrm{HCCl}_{3}$ & 30 \\
3 & $\mathrm{HCCl}_{3}$ & 40 \\
4 & $\mathrm{HCCl}_{3}$ & 40 \\
$5-10$ & $\mathrm{HCCl}_{3}$ & - \\
11 & $\mathrm{CHCl}_{3}: \mathrm{MeOH}^{2}(95: 5)$ & 10 \\
12 & $\mathrm{CHCl}_{3}: \mathrm{MeOH}(9: 1)$ & 10 \\
13 & $\mathrm{CHCl}_{3}: \mathrm{MeOH}(9: 1)$ & 310 \\
14 & $\mathrm{CHCl}_{3}: \mathrm{MeOH}(9: 1)$ & 170 \\
15 & $\mathrm{CHCl}_{3}: \mathrm{MeOH}(9: 1)$ & 130 \\
\hline
\end{tabular}

The progress of Alumina fractionation was followed by TLC. Chloroform solutions of standard phosphatyldilcholine (PC), crude extract (CE) and alumina fractions (1 - 4 and 11 - 15) were prepared and applied to silica gel TLC plates. Fractions 5 to 10 were devoid of any organic compound (Table 1) and were not included.

Figure 1A shows the results of TLC which was developed with solvent system TLC-A, after charring at $120^{\circ} \mathrm{C}$. The first 4 fractions contained fatty acids and other contaminants. In fraction 11 and 12, where the column solvent was changed, (see Table 1) there were residual apolar contaminants. Fraction 12 contained some lecithin but was contaminated. In this solvent system, the lecithin and other phospholipids remain in the origin and they were detected by the blue color developed after molybdate spray. In fractions 13 - 15 no other contaminants were seen with TLC-A solvent system.

In TLC-B solvent system, lecithin and more polar compounds migrate. As can be seen in Figure 1B, in fractions 13 to 15 only one spot of lecithin is seen. There were no contaminants with lower retention factor $\left(\mathrm{R}_{\mathrm{F}}\right)$ than lecithin (such as lysolecithin) indicating that these fractions contained pure lecithin.

Lecithin from egg yolk is a mixture of zwitterionic phospholipids containing two fatty acid chains (Scheme 2). Positional distribution of saturated and unsaturated fatty acids on 


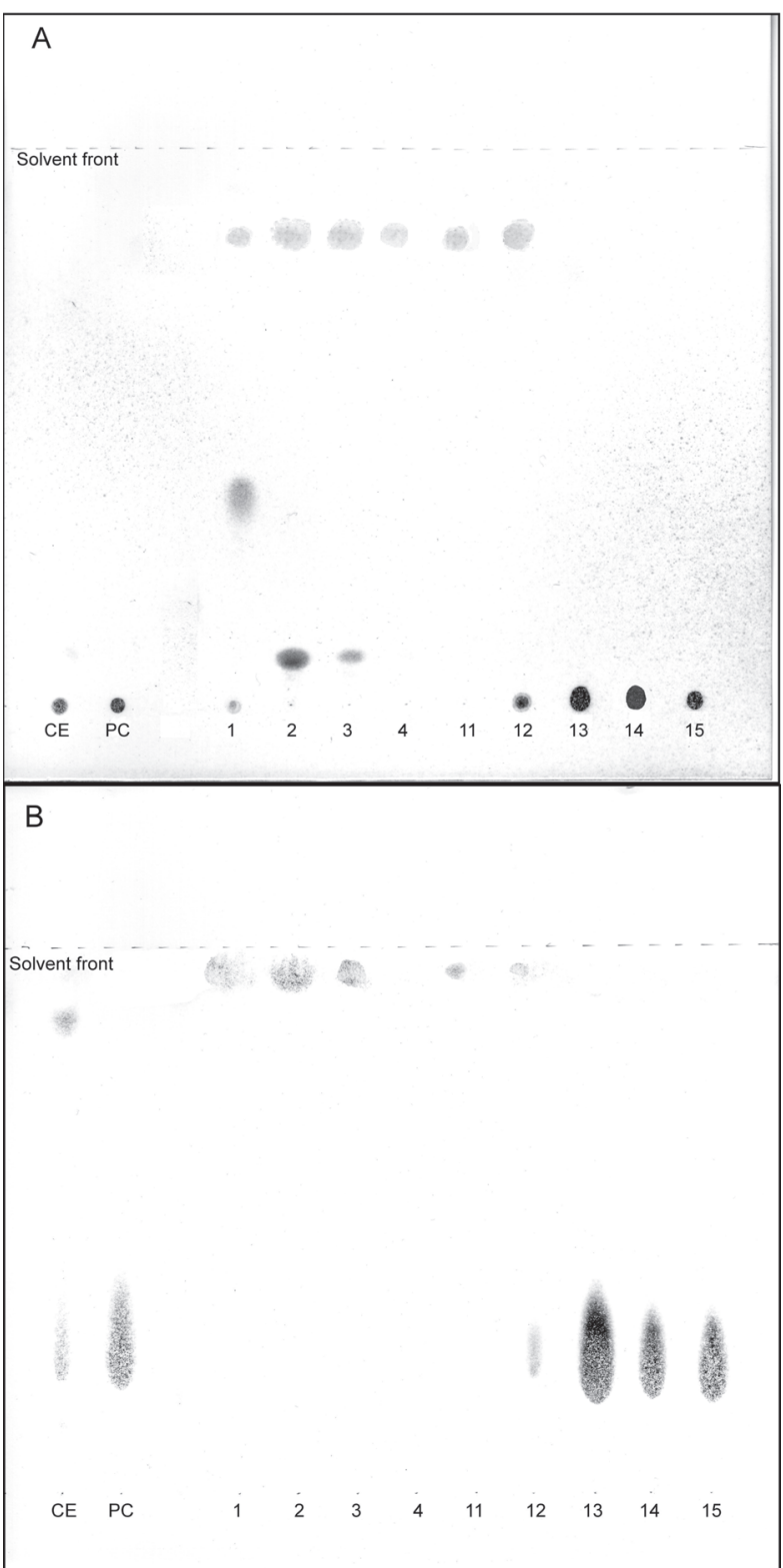

Figure 1. Thin layer chromatography of Alumina column fractions. Numbers refer to alumina fractions (Table 1). Plates were developed with the solvent systems: (A) TLC-A; (B) TLC-B. (CE) lecithin crude extract; (PC) Lecithin standard

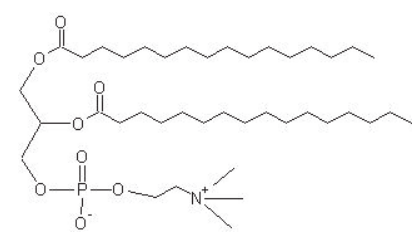

Scheme 2. Molecular structure of 1,2-dipalmitoyl-sn-glycero-3Phosphatidylcholine

egg lecithin is known ${ }^{15}$ and the nature of the fatty acids vary with chicken diet composition. ${ }^{16}$ The number of carbons of the fatty acid chains range from 14 to 22 and 0 to 6 double bonds can be present in each fatty acid. ${ }^{17,18}$ Fractions $13-15$ were analyzed by ESI Mass spectra, in the positive mode, where the molecular mass of the lecithin analogs can be determined (Figure 2).

All the lecithin-containing column fractions exhibited $\mathrm{m} / \mathrm{z}$ peaks between 750 and 900 (Figure 2). These $\mathrm{m} / \mathrm{z}$ peaks can be attributed
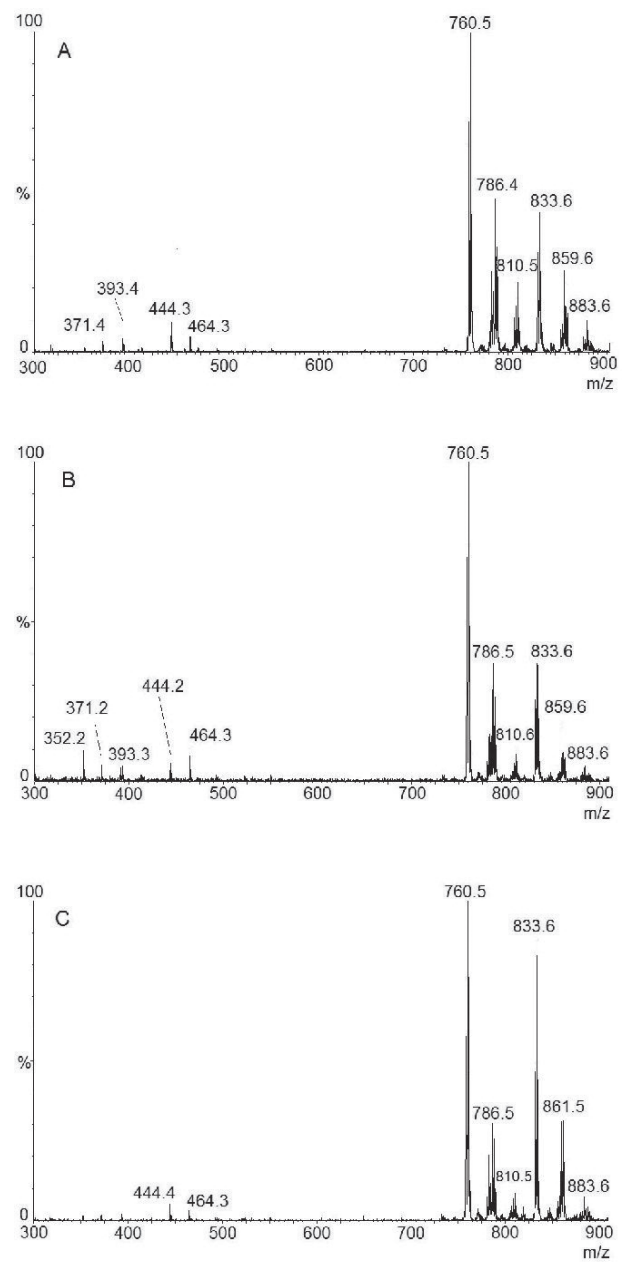

Figure 2. ESI mass spectra of fractions $13(\boldsymbol{A}), 14(\boldsymbol{B})$ and $15(\boldsymbol{C})$

to differences in the carbon number and insaturations of fatty acids chains of the lecithins. The predominance of a peak with $\mathrm{m} / \mathrm{z}$ of 760 is coincident with previous data that demonstrated that palmitoyl, oleyl phosphatidylcholine $(\mathrm{m} / \mathrm{z}=760.5)$ constitutes ca. $35 \%$ of the egg phosphatydilcholine, followed by the stearoyl, linoleyl phosphatydilcholine $(m / z=786.4) .{ }^{5}$ Some of the $m / z$ peaks, observed in Figure 2, can be attributed to phosphatidylcholines (Scheme 2) with different fatty acid composition (Table 2).

Table 2. Lecithin fatty acid composition

\begin{tabular}{lc}
\hline Lipid chains; $\mathrm{N}^{0}$ Double bonds & $m / z$ \\
\hline C16,C18; 1 & 760.5 \\
C18,C18; 2 & 786.5 \\
C18,C20; 4 & 810.5 \\
C20,C20; 4 & 833.6 \\
C20,C22; 4 & 861.5 \\
C22:1,C22; & 883.6 \\
\hline
\end{tabular}

Several authors have used alumina in the purification of lecithin. ${ }^{4,5}$ In our experience, the extent of fatty acid contamination in the purified lecithin is extremely dependent on the chloroform/ methanol ratio used in the lecithin elution using alumina. We have found that the best and easier preparation is the one described by Singleton et al. ${ }^{5}$ with a chloroform/methanol ratio of 9:1, v/v. This solvent ratio is adequate for lecithin elution, but, in our hands, the lecithin is invariably contaminated with apolar compounds. The 
modification proposed in this work is the extensive washing of the alumina column with chloroform until the contaminants cannot be evidenced by TLC using solvent system A. Subsequently, a stepwise increase in the methanol content of the solvent mixture (chloroform:methanol 95:5 and 9:1 v/v) which eliminate the remaining contaminants and allow pure lecithin elution (Figure 1).

\section{CONCLUSION}

Despite the wide variety of procedures describing lecithin purification no easy, low-cost methods, provide samples devoid of free fatty acids. Here adaptation of previous methodology allowed us to rapidly obtain purified lecithin without fatty acid contaminants at a low cost.

\section{ACKNOWLEDGMENTS}

FAPESP, CNPq. We thank Dr. P. Di Mascio for the ESI mass spectra facilities and the technical assistance of F. M. Prado.

\section{REFERENCES}

1. Levene, P. A.; Simms, H. S.; J. Biol. Chem. 1921, 48, 185.

2. Levene, P. A.; J. Biol. Chem. 1927, 72, 587.

3. Pangborn, M. C.; J. Biol. Chem. 1951, 188, 471.

4. Hanahan, D. J.; Dittmer, J. C.; Warashina, E.; J. Biol. Chem. 1957, 228, 685.

5. Singleton, W. S.; Gray, M. S.; Brown, M. L.; White, J. L.; JAOCS 1965 , $42,53$.

6. Radin, N. S.; J. Lipid Res. 1978, 19, 922.

7. Nielsen, J. R.; Lipids 1980, 15, 481.

8. Amari, J. V.; Brown, P. R.; Grill, C. M.; Turcotte, J. G.; J. Chromatogr., A 1990, 517, 219.

9. Abidi, S. L.; Mounts, T. L.; J. Chromatogr., A 1992, 598, 209.

10. Kuksis, A.; Biochim. Biophys. Acta 1992, 1124, 205.

11. Zhang, W. N.; Hu, Z. X.; Feng, Y. Q.; Da, S. L.; J. Chromatogr., A. 2005, 1068, 269.

12. Velonia, K. C. J.; Feiters, M. C.; Rowan, A. E.; Nolte, R. J. M. In Nanoscale Assembly: Chemical Techniques; Ed. Springer: New York, 2005, chapter 7.

13. Gluck, U. G. J-O.; Gluck, R.; J. Virol. 1999, 73, 7780.

14. Kamp, H. H.; Wirtz, K. W. A.; Baer, P. R.; Slotboom, A. J.; Rosenthal, A. F.; Paultauf, F.; van Deenen, L. L. M.; Biochemistry 1977, 16, 1310.

15. Tattrie, N. H.; J. Lipid Res. 1959, 1, 60.

16. Navarro, J. G.; Saavedra, J. C.; Borie, F. B.; Caiozzi, M. M.; J. Sci. Food Agric. 1972, 23, 1287.

17. Kai, M.; Joshita, T.; Saga, M.; J. Biochem. 1963, 54, 403

18. Kuksis, A.; Marai, L.; Lipids 1967, 2, 217. 